\title{
QUANTIFICATION OF ISOORIENTIN IN THREE VARIETIES OF PASSION FRUIT PEEL ETHANOLIC EXTRACT BY HIGH PERFORMANCE LIQUID CHROMATOGRAPHY MASS SPECTROMETRY
}

\author{
E. D. L. Putra ${ }^{1}$, N. Nazliniwaty ${ }^{2}$, F. R. Harun ${ }^{1}$ and N. Nerdy ${ }^{3, *}$ \\ ${ }^{1}$ Department of Pharmaceutical Chemistry, Faculty of Pharmacy, Universitas Sumatera Utara, \\ Padang Bulan, Medan Baru, Medan, Sumatera Utara, Indonesia, 20155 \\ ${ }^{2}$ Department of Pharmaceutical Technology, Faculty of Pharmacy, Universitas Sumatera Utara, \\ Padang Bulan, Medan Baru, Medan, Sumatera Utara, Indonesia, 20155 \\ ${ }^{3}$ Department of Pharmacy, Faculty of Pharmacy, Institut Kesehatan Deli Husada Deli Tua, Deli \\ Tua Timur, Deli Tua, Deli Serdang, Sumatera Utara, Indonesia, 20355 \\ *E-mail: nerdy190690@gmail.com
}

\begin{abstract}
The utilization of passion fruit peel is still very minimal and has not been used optimally. The phytochemical content contained in the passion fruit peel is very diverse and can provide diverse pharmacological activities. The different varieties of passion fruit peel that are seen from different peel colors, allow causing differences in the phytochemical content and differences in the pharmacological effects in the passion fruit peel. Analysis of isoorientin content contained in passion fruit peel extract with different varieties (purple, red, and yellow) of passion fruit by high-performance liquid chromatography mass spectrometry methods. The passion fruit peel with different varieties was extracted by maceration with ethanol. Analysis of the content of isoorientin was carried out by high performance liquid chromatography mass spectrometry method. Stationary phase octadecylsilane column; Mobile phase used is a gradient system with aqueous formic acid $0.1 \%(\mathrm{~A})$ and acetonitrile (B). The content of isoorientin in ethanolic extract of purple passion fruit peel was $75.14 \mathrm{mg}$ of isoorientin per $\mathrm{kg}$ of dried simplicial. The content of isoorientin in ethanolic extract of red passion fruit peel was $50.16 \mathrm{mg}$ of isoorientin per $\mathrm{kg}$ of dried simplicial. The content of isoorientin in ethanolic extract of yellow passion fruit peel was $30.11 \mathrm{mg}$ of isoorientin per kg of dried simplicia. There is a significant difference in the content of isoorientin in ethanolic extract of passion fruit peel with different varieties. The highest isoorientin content is in ethanolic extract of purple passion fruit peel. The lowest isoorientin content is in ethanolic extract of yellow passion fruit peel.
\end{abstract}

Keywords: Isoorientin, Ethanolic Extract, Peel, Passion Fruit, Varieties.

(C) RASĀYAN. All rights reserved

\section{INTRODUCTION}

Passion fruit (Passiflora sp.) is one of the fruits that grow in mountain areas in tropical countries. Passion fruit has a very distinctive taste and aroma, so it is widely consumed by the public at a large amount. Passion fruit is in great demand so it is one of the plants that are exported to other countries. Passion fruit is processed into many drinks that give a fresh taste to those who consume passion fruit ${ }^{1,2}$.

The utilization of passion fruit peel is still very minimal and has not been used optimally ${ }^{3,4}$. The phytochemical content contained in the passion fruit peel is very diverse and can provide diverse pharmacological activities. One of the ingredients that have a high pharmacological effect and is found in quite high amounts in passion fruit peel is isoorientin which is a flavonoid compound ${ }^{5}$. Isoorientin has many pharmacological effects, as an antibacterial ${ }^{5}$, antiretroviral ${ }^{6}$, and antidiabetic ${ }^{7}$, and antioxidant ${ }^{8}$.

Passion fruit has a variety of varieties that grow in the territory of Indonesia. Variety differences can be distinguished from the size, taste, and color of the peel. Passion fruit varieties that grow in the region of Indonesia were purple passion fruit (purple color of peel, sour taste, and small size), red passion fruit (red Rasayan J. Chem., 13(2), 968-972(2020) http://dx.doi.org/10.31788/RJC.2020.1325645 
RASĀYAN J. Chem.

Vol. 13 | No. 2 |960 - 967| April - June | 2020

color peel, sweet and sour taste, and medium-size), and yellow passion fruit (yellow color peel, sweet taste, and big size). The different varieties of passion fruit peel that are seen from different peel colors, allow causing differences in the phytochemical content and differences in the pharmacological effects in the passion fruit peel ${ }^{9}$.

The extract is one of the natural material preparations obtained through the extraction process using certain solvents and certain techniques that contain certain secondary metabolite compounds. Extracts in the pharmaceutical field are widely used and obtained from natural ingredients making it easier to manufacture pharmaceutical preparations ${ }^{10}$. In this research, an analysis of isoorientin content contained in passion fruit peel extract with different varieties (purple, red, and yellow) of passion fruit by high performance liquid chromatography mass spectrometry methods.

\section{EXPERIMENTAL}

\section{Materials}

Materials used in this research were passion fruit peels with different varieties (purple passion fruit peels, red passion fruit peels, and yellow passion fruit peels) obtained from passion fruit farmers in Gundaling, Berastagi, Karo, North Sumatra, Indonesia; water (Brataco); acetonitrile (Merck); formic acid (Merck); ethanol (Merck); and other pro analysis grade reagents from Merck.

\section{Tools}

Tools used in this research were high performance liquid chromatography mass spectrometer (Agilent); octadecylsilane column $4.6 \mathrm{~mm} \times 250.0 \mathrm{~mm}$ with particle size $5.0 \mu \mathrm{m}$ (Phenomenex); water purification system (Merck); blender (Philips), cutter (Kenko), measuring glass (Iwaki); and other glassware from Iwaki.

\section{Preparation of Extract}

The preparation of extract is a modification of the method of Adhikari et al., 2018. The passion fruit peel with different varieties (purple passion fruit peel, red passion fruit peel, and yellow passion fruit peel) was collected, washed, and dried. The simplicia (dried passion fruit peel) was powdered. The simplicia powder, inserted into a closed vessel, added ethanol as the solvent (7,5 times) of the simplicia, left for 5 days and stirred frequently, and filtered the mixture. The pulp was inserted again into a closed vessel, added ethanol as the solvent $(2,5$ times) of the simplicia, left for another 5 days and stirred frequently, filtered the mixture, and mixed with the first filtrate ${ }^{11}$. The diluted extract was evaporated with a rotary evaporator and free dryer and obtained the viscous extract.

\section{Analysis of Isoorientin in Passion Fruit Peel Extract}

Analysis of the content of isoorientin was carried out by high performance liquid chromatography mass spectrometry method. The chromatography condition used in this research is a modification of the method of Zhang et al., 2018. The standard solution is prepared by carefully weighing isoorientin in the amount of $10 \mathrm{mg}$, inserted into a $100 \mathrm{~mL}$ volumetric flask, added $60 \mathrm{~mL}$ of ethanol, shaken until dissolved, sufficient with ethanol to the mark line, shaken until homogeneously mixed (obtained isoorientin stock solution with a concentration of $100 \mu \mathrm{g}$ per $\mathrm{mL}$ ). The standard isoorientin stock solution is pipetted $1 \mathrm{~mL}$; $3 \mathrm{~mL} ; 5 \mathrm{~mL} ; 7 \mathrm{~mL}$; and $9 \mathrm{~mL}$; put separately into a $10 \mathrm{~mL}$ volumetric flask, diluted with ethanol to the mark line, shaken until homogeneously mixed (obtained isoorientin solution with a concentration of 10 $\mu \mathrm{g}$ per $\mathrm{mL} ; 30 \mu \mathrm{g}$ per $\mathrm{mL} ; 50 \mu \mathrm{g}$ per $\mathrm{mL} ; 70 \mu \mathrm{g}$ per $\mathrm{mL}$; and $90 \mu \mathrm{g}$ per $\mathrm{mL}$; $\mathrm{mL}$ ). The sample solution was prepared by carefully weighing an amount of $10 \mathrm{mg}$ from each sample (ethanolic extract of purple passion fruit peel; ethanolic extract of red passion fruit peel; ethanolic extract of yellow passion fruit peel), inserted separately into a $100 \mathrm{~mL}$ volumetric flask, added with $60 \mathrm{~mL}$ of ethanol, shaken until dissolved, added with ethanol to mark line, shaken until homogeneously mixed. High performance liquid chromatography system consists of stationary phase used is an octadecylsilane column; mobile phase used is a gradient system with aqueous formic acid $0.1 \%$ (A) and acetonitrile (B) ratio of $95 \%$ (A) and $5 \%$ (B), decreasing B to $75 \%$ in 5 minutes, maintaining for 10 minutes, increasing A to $95 \%$ in 5 minutes, and keeping constant for 5 minutes, so that the total run time was 25 minutes for each sample analysis; the 
RASĀYAN J. Chem.

Vol. 13 | No. 2 |960 - 967| April - June | 2020

flow rate used is $0.8 \mathrm{~mL}$ per minute with a 1: 1 split ratio, the volume of injection of the sample is $25 \mu \mathrm{L}$. The mass spectrometry system consists of quadrupole mass spectrometer with an electron spray ionization source in the negative ionization mode; detection for quantification in selected ion monitoring mode with monitored molecular mass 447 to 449 dalton, spray voltage of $30 \mathrm{kV}$; vaporizer temperature $300^{\circ} \mathrm{C}$; the capillary temperature was $270^{\circ} \mathrm{C}$; sheath gas used was nitrogen; auxiliary gas used was nitrogen. The standard solution and sample solution were analyzed separately by injecting standard solutions and sample solutions, recording the peak area, and calculating the isoorientin content in the extract $^{12}$.

\section{RESULTS AND DISCUSSION}

Analysis of isoorientin standards at a concentration of $0 \mu \mathrm{g}$ per $\mathrm{mL}, 10 \mu \mathrm{g}$ per $\mathrm{mL}, 30 \mu \mathrm{g}$ per $\mathrm{mL}, 50 \mu \mathrm{g}$ per $\mathrm{mL}, 70 \mu \mathrm{g}$ per $\mathrm{mL}$, and $90 \mu \mathrm{g}$ per $\mathrm{mL}$ to determine the linearity of the relationship between concentration and area. The area data of isoorientin standard analysis results at various concentrations can be seen in Table-1. The linearity curve of the relationship between isoorientin concentrations and the area can be seen in Fig.-1.

Table-1: The Area Data of Isoorientin Standard Analysis Results at Various Concentrations

\begin{tabular}{c|c|c}
\hline Data & X (Concentration in $\mu \mathrm{g}$ per $\mathrm{mL})$ & Y (Area in Absorbance Unit) \\
\hline 1 & 0,0000 & 0,0000 \\
\hline 2 & 10,0000 & 103051,0000 \\
\hline 3 & 30,0000 & 309064,0000 \\
\hline 4 & 50,0000 & 513214,0000 \\
\hline 5 & 70,0000 & 710534,0000 \\
\hline 6 & 90,0000 & 920624,0000 \\
\hline
\end{tabular}

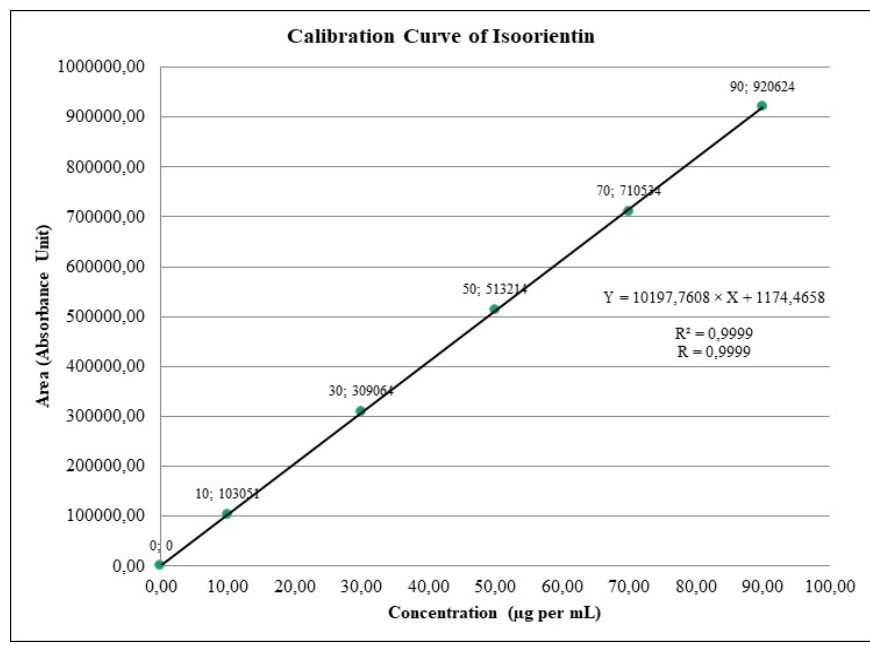

Fig.-1: The Linearity Curve of the Relationship between Isoorientin Concentrations and the Area From the Data

Figure-1 shows the linearity curve of the relationship between isoorientin concentrations and the area from the data and the results of determining the linearity relationship between concentration and area of the isoorientin standard at a concentration of $0 \mu \mathrm{g}$ per $\mathrm{mL}, 10 \mu \mathrm{g}$ per $\mathrm{mL}, 30 \mu \mathrm{g}$ per $\mathrm{mL}, 50 \mu \mathrm{g}$ per $\mathrm{mL}, 70$ $\mu \mathrm{g}$ per $\mathrm{mL}$, and $90 \mu \mathrm{g}$ per $\mathrm{mL}$ obtained by the regression equation is $\mathrm{Y}=10197.7608 \times \mathrm{X}+1174.4658$ with $\mathrm{R}^{2}$ value 0.9999 and $\mathrm{R}$-value 0.9999 . These results indicate that there is a linear relationship between isoorientin concentrations and isoorientin areas in the analysis of high-performance liquid chromatography.

The correlation coefficient $(\mathrm{R})$ obtained is greater than 0.90 which means that there is a very strong correlation between two variables ${ }^{13}$. The results of the study of the correlation coefficient values obtained means that there is a correlation between isoorientin concentration and isoorientin area. The results of the study of the determination coefficient obtained means that isoorientin concentration can be determined through the isoorientin area using the regression equation. 
RASĀYAN J. Chem.

Vol. 13 | No. 2 |960 - 967| April - June | 2020

The isoorientin standard linearity test data is continued by calculating the detection limit and the quantitation limit. The limit of detection value is $0.3776 \mu \mathrm{g}$ per $\mathrm{mL}$ and the limit of quantitation value is $1.1442 \mu \mathrm{g}$ per $\mathrm{mL}$. The limit of detection is the lowest concentration that can be detected by an analysis method. Limit of quantitation is the lowest concentration that can be analyzed quantitatively by an analysis method ${ }^{14}$. The results showed that isoorientin can be detected and quantitated in low concentrations by the method of high performance liquid chromatography mass spectrometry; which means that the analytical method has good sensitivity for detecting and quantifying the isoorientin.

Determination of isoorientin levels in ethanolic extract of purple passion fruit peel, ethanolic extract of red passion fruit peel, and ethanolic extract of yellow passion fruit peel is done by high performance liquid chromatography mass spectrometry. The isoorientin content in different varieties of passion fruit peel ethanolic extract can be seen in Table-2.

Table-2: The Isoorientin Content in Different Varieties of Passion Fruit Peel Ethanolic Extract

\begin{tabular}{c|cc}
\hline Number & Sample & Isoorientin Content \\
\hline 1 & Ethanolic Extract of Purple Passion Fruit Peel & $(75.14 \pm 3.32) \mathrm{mg} \mathrm{per} \mathrm{kg}$ \\
\hline 2 & Ethanolic Extract of Red Passion Fruit Peel & $(50.16 \pm 2.30) \mathrm{mg} \mathrm{per} \mathrm{kg}$ \\
\hline 3 & Ethanolic Extract of Yellow Passion Fruit Peel & $(30.11 \pm 1.51) \mathrm{mg} \mathrm{per} \mathrm{kg}$ \\
\hline
\end{tabular}

Data from the determination of isoorientin content in passion fruit peels is known that the highest isoorientin content is in ethanolic extract of purple passion fruit peel and the lowest isoorientin content is in ethanolic extract of yellow passion fruit peel. These results indicate that differences in varieties affect the difference in the phytochemical content of secondary metabolites in plant parts ${ }^{15}$.

A flavonoid compound is a polyphenol compound that has 15 carbon atoms arranged in a C6-C3-C6 configuration, meaning that the carbon framework consists of two C6 groups (substituted benzene rings) connected by a three-carbon aliphatic chain ${ }^{16}$. Flavonoids are found in plants, which contribute to producing pigments (yellow, red, orange, blue, or purple) from the plant parts (fruit, flower, or leaf) ${ }^{17}$. Flavonoids are considered as the most important phytochemicals in food, which have broad biological benefits for humans ${ }^{18}$.

An analysis of the content of isoorientin has previously been carried out on passion fruit pulp and passion fruit peel. The content of isoorientin in passion fruit pulp obtained a value of $16.23 \mathrm{mg}$ of isoorientin per $\mathrm{L}$ of pulp ${ }^{19}$. The content of isoorientin in passion fruit peel obtained a value of $92.28 \mathrm{mg}$ of isoorientin per $\mathrm{L}$ of extract ${ }^{20}$. The results of the research on isoorientin content showed that the content of isoorientin in ethanolic extract of purple passion fruit peel was $75.14 \mathrm{mg}$ of isoorientin per $\mathrm{kg}$ of dried simplicia, the content of isoorientin in ethanolic extract of red passion fruit peel was $50.16 \mathrm{mg}$ of isoorientin per $\mathrm{kg}$ of dried simplicia, and the content of isoorientin in ethanolic extract of yellow passion fruit peel was 30.11 $\mathrm{mg}$ of isoorientin per $\mathrm{kg}$ of dried simplicia.

The value of isoorientin content obtained in this study is different from the value of isoorientin content from previous studies. This may be due to differences in locations where the growth of passion fruit will affect the content of secondary metabolites in plants ${ }^{21}$. The difference in the location of growth will also greatly affect the temperature of the place of growth, and the condition of the soil (soil nutrition) of growth which results in differences in the content of secondary metabolites in plants ${ }^{22}$.

\section{CONCLUSION}

There is a significant difference in the content of isoorientin in ethanolic extract of passion fruit peel with different varieties. The highest isoorientin content is in ethanolic extract of purple passion fruit peel. The lowest isoorientin content is in ethanolic extract of yellow passion fruit peel.

\section{ACKNOWLEDGMENT}

The research was funded by the University of Sumatera Utara (USU) by the TALENTA USU Research Implementation Contract for Fiscal Year 2019 with Contract Number 4167/UN5.1.R/PPM/2019 on 01 April 2019.

\section{REFERENCES}

1. C. Gutiérrez-Chacón C, F. Fornoff, R. Ospina-Torres, and A.M. Klein, Journal of Economic Entomology, 20(10), 1(2018), DOI:10.1093/jee/toy133 
2. F.G. Faleiro, N.T.V. Junqueira, T.G. Junghans, O.N. de Jesus, D. Miranda, and W.C. Otoni, Revista Brasileira de Fruticultura, 41(2), e-155(2019), DOI:10.1590/0100-29452019155

3. C.Y. Cheok, N.M. Adzahan, R.A. Rahman, N.H.Z. Abedin, N. Hussain, R. Sulaiman, and C.H. Chong, Critical Reviews in Food Science and Nutrition, 5, 1(2017), DOI: 10.1080/10408398.2016.1176009

4. N.M.V. de Toledo, A.C. de Camargo, P.B.M. Ramos, D.C. Button, D. Granato, and S.G. CanniattiBrazaca, Beverages, 4(1), 47(2018), DOI:doi.org/10.3390/beverages4030047

5. N. Nerdy, and K. Ritarwan, Open Access Macedonian Journal of Medical Sciences, 7(4), 536(2019), DOI: 10.3889/oamjms.2019.153

6. S.D.S.F. Marques, R.M.F. Libonati, A.U.O. Sabaa-Srur, R. Luo, P. Shejwalkar, K. Hara, T. Dobbs, and R.E. Smith, Revista Brasileira de Farmacognosia, 26, 420(2016), DOI: 10.1016/j.bjp.2016.03.002

7. H.X. Li, R. Gao, J. Zheng, J.J. Zhang, D.W. Zhang, Z.C. Dong, T. Zhou, and H.B. Li, International Journal of Traditional and Natural Medicines, 6(1), 26(2016).

8. D.S. Lima, N.B.A. Duarte, D.L.C. Barreto, G.P. de Oliveira, J.A. Takahashi, S.P. Fabrini, and D. Sande, Ciência Rural, Santa Maria, 4890, 20180076(2018), DOI:10.1590/0103-8478cr20180076

9. L.C.R. dos Reis, E.M.P Facco, M. Salvador, S.H. Flores, A.D.O. Rios, Journal of Food Science and Technology, 55(7), 2679(2018), DOI:10.1007/s13197-018-3190-2

10. A. Altemimi, N. Lakhssassi, A. Baharlouei, D.G. Watson, and D.A. Lightfoot, Plants, 6(1), 42(2017), DOI: $10.3390 /$ plants6040042

11. P. Adhikari, A. Pandey, V. Agnihotri, and V. Pande, Research in Pharmacy, 8, 1(2018), DOI: 10.25081/rip.2018.v8.3487

12. S. Zhang, Y. Xie, J. Wang, Y. Geng, Y. Zhou, C. Sun, and G. Wang, Revista Brasileira de Farmacognosia, 28, 156(2018), DOI:10.1016/j.bjp.2018.01.004

13. P. Schober, C. Boer, and L.A. Schwarte, Anesthesia \& Analgesia, 126(5), 1763(2018), DOI: 10.1213/ANE.0000000000002864

14. W. Zhu, G. Liang, W. Qiu, A. Clarke, C. Kolarik, and S. Mozzo, Advances in Pharmaceutical Analysis, 31(s10), 7(2018).

15. M.G. Figueroa-Pérez, I.F. Pérez-Ramírez, O. Paredes-López, C. Mondragón-Jacobo, and R. ReynosoCamacho, International Journal of Food Properties, 21(1), 1728(2018), DOI: $10.1080 / 10942912.2016 .1206126$

16. T.Y. Wang, Q. Li, and K.S. Bi, Asian Journal of Pharmaceutical Sciences, 13, 12(2018), DOI: 10.1016/j.ajps.2017.08.004

17. S.A. Saganuwan, European Journal of Medicinal Plants, 5(1), 1(2018), DOI: $10.9734 / \mathrm{EJMP} / 2018 / 43766$

18. A.N. Panche, A.D. Diwan, and S.R. Chandra, Journal of Nutritional Science, 5, e47(2016), DOI: $10.1017 /$ jns.2016.41

19. M.L. Zeraik, and J.H. Yariwake, Microchemical Journal, 96, 86(2010), DOI:10.1016/j.microc.2010.02.003

20. M.L. Zeraik, J.H. Yariwake, J.N. Wauters, M. Tits, and L. Angenot, Quimica Nova, 35(3), 541(2012).

21. A.C.M.A. Araújo, E.G.T. Menezes, A.W.C. Terra, B.O. Dias, E.R. de Oliveira, and F. Queiroz, Food Science and Technology, Campinas, 38(Suppl.1), 203(2018), DOI:10.1590/fst.19417

22. J. Wu, J. Drappier, G. Hilbert, S. Guillaumie, Z. Dai, L. Geny, S. Delrot, P. Darriet, C. Thibon, and P. Pieri, International Viticulture and Enology Society, 2, 321(2019), DOI:10.20870/oenoone.2019.53.2.2434

[RJC-5645/2019] 